\title{
Predicting the loss to follow-up of HIV-infected patients on ART in a rural area in South Africa using generalized gamma distributions
}

Pepukai Bengura ( $\boldsymbol{\sigma}$ bpenaldo@yahoo.com )

University of South Africa

\section{Research Article}

Keywords: HIV/AIDS, loss to follow-up, ART, Kaplan-Meier, risk factors, Gamma distributions

Posted Date: February 16th, 2021

DOI: https://doi.org/10.21203/rs.3.rs-208706/v2

License: (c) (1) This work is licensed under a Creative Commons Attribution 4.0 International License.

Read Full License 


\title{
Predicting the loss to follow-up of HIV-infected patients on ART in a rural area in South Africa using generalized gamma distributions
}

Pepukai Bengura, Department of Statistics, University of South Africa, Pretoria.

\begin{abstract}
Background - Long-term regular follow-up and high retention are the anticipated outcomes for the wellness and longevity of HIV/AIDS patients on antiretroviral treatment. However, these anticipated outcomes are marred by patient loss to follow-up (LTFU) which is currently exacerbated by the COVID-19 pandemic. This study aims to determine the prevalence and predictors of LTFU among HIV/AIDS patients on ART at two rural district hospitals in South Africa.

Methods - This is an observational study whereby a cohort of HIV/AIDS patients was retrospectively followed from 2010 to 2017 until loss to follow-up occurred or until the end of the observation period at Carolina and Embhuleni hospitals. A study was undertaken among children, adolescents and adults living with HIV/AIDS and attending ART clinic between January 1, 2010 and June 30, 2017. Loss to follow up was defined as not taking an ART refill for a period of 90 days or longer from the last attendance for refill and not yet classified as 'dead' or 'transferred-out'. Patient information was obtained from the routine hospitals' records, and the data were analysed using Generalized gamma distribution to identify the predictors of loss to follow-up among HIV/AIDS patients while KaplanMeier model was used to estimate and compare the LTFU survival probabilities of heterogenous groups among the patients.
\end{abstract}

Results - Of the 357 patients, $60.5 \%$ were female. The mean (SD) age of the cohort was 36.2 (14.1), 15.4 (3.5), and 5.1 (3.5) years for adults, adolescents, and children, respectively. From 357 HIV/AIDS patients, 93 (26.05\%) were lost to follow-up. Empirical results produced Weibull distribution as the best fit to the data. The Weibull model determined the factors associated with patient loss to follow up as: regimen EFV+D4T+3TC [HR: 2.0 CI;(1.3-3.1)], regimen EFV+AZT+3TC [HR: 2.9 CI;(1.3-6.4)], regimen EFV+3TC+TDF [HR: 10.0 CI;(3.9-25.9)], regimen NVP+3TC+TDF [HR: $10.6 \mathrm{CI}$;(1.862.4)], follow up CD4 [HR: 1.0 CI;(1.0-1.0)], $\log$ (follow up viral load) [HR: 0.8 CI;(0.7-0.9)], marital status (married) [HR: $0.4 \mathrm{CI} ;(0.3-0.8)]$, marital status (cohabitation) [HR: $0.6 \mathrm{CI} ;(0.3-0.9)]$, ART adherence (fair) [HR: 2.4 CI;(1.3-3.4)], ART adherence (good) [HR: 4.6 CI;(2.2-9.5)] and age [HR: $1.02 \mathrm{CI} ;(1.0-1.04)]$.

Discussion - Effective control and tracing measures in the at-risk population and in defaulters need to be stepped up especially during this COVID-19 pandemic period, to improve retention in hospitals. There is also need for careful adherence counseling and assessment of medication supplies.

Conclusion - LTFU is more pronounced among females and is highest among adolescents. Patients with increased risk for LTFU were consistent with ART regimens, viral load, age, CD4 count, adherence and marital status.

Keywords: HIV/AIDS, loss to follow-up, ART, Kaplan-Meier, risk factors, Gamma distributions. 


\section{Background}

HIV/AIDS has been a major health problem worldwide for more than three decades now. According to the UNAIDS global statistics; since the beginning of the epidemic, 75.7 million people have been infected with the HIV virus, about 32.7 million people have died of HIV and 38 million people were living with HIV at the end of 2019. According to Avert (2018), South Africa has the biggest and most high-profile HIV epidemic in the world, with estimated 7.7 million living with HIV in 2019. South Africa's Mpumalanga province has the second highest HIV prevalence rate after KwaZulu-Natal province. Gert Sibande district which is in Mpumalanga province is leading all districts in the country with 46.1\% HIV prevalence rate (Motsoaledi, 2013). Gert Sibande district has Albert Luthuli as one of its municipalities whose HIV prevalence stood at 43.2\% (Nkosi, 2017). HIV prevalence in South Africa currently stands at 20.4\% (Avert, 2018).

The ART treatment has shown promising results in the reduction of HIV transmission and in HIV/AIDS related morbidity and mortality. According to WHO report, ART has prevented an estimate 4.2 million deaths in Low and Middle Income Countries (LMICs) in 2013 (WHO, 2014). Despite improved and highly successful programmatic coverage with ART, significant numbers of patients drop out of care at various points along the treatment pathway and thereby negatively impacting on the immunological benefit of ART. Defaulting on ART increases AIDS-related morbidity, mortality and hospitalisations. LTFU in patients receiving ART can result in serious consequences, such as discontinuation of treatment, drug toxicity, treatment failure due to poor adherence and drug resistance (Kaplan et al., 2000; Taiwo, 2009). The LTFU results in an increased risk of death of up to $40 \%$ as in studies of patients LTFU in sub-saharan Africa (Chammartin et al., 2018 ; Brinkhof et al., 2009). It is essential to understand how and why people drop out of treatment programmes, since the retention of people on ART and ensuring adherence to treatment are critical determinants of successful long-term outcomes (Berheto et al., 2014). Many ART programmes and cohort studies have witnessed many patients defaulting ART adherence through LTFU. According to De La Mata et al. (2017), studies in Sub-Saharan Africa have reported high rates of LTFU within 6 months following ART initiation. More than half the patients receiving ART in two care and treatment centres in Tanzania were LTFU within 3 months of ART initiation. In addition, patients who are LTFU often have high mortality rates, particularly from low-income countries. Unreported deaths in LTFU patients can also bias findings from 
analyses, particularly in time-to-event analyses. Studies have reported an association between episodes of LTFU and poor outcomes in HIV-positive patients in both low and high resource settings (McManus et al., 2015). According to Berheto et al. (2014), poor nutritional status, lower CD4 count, TB co-infection, advanced clinical staging, younger age, adverse drug reactions, gaps in services and accessibility to services are some of the predictors reported to be associated with LTFU. The identification of specific patients who may be at increased risk of LTFU can prompt preventive strategies and can direct the introduction of support to pre-empt discontinuous clinical attendance and improve treatment adherence (McManus et al., 2015). Optimal long-term outcomes require consistent retention in care for ensuring on-time medication refill, evaluating treatment response, monitoring for adverse effects, and delivering additional clinical interventions (Geng et al., 2016).

Determination of the risk to LTFU is therefore crucial to allow early intervention to minimize or prevent LTFU. Data from 23 countries indicate that average retention for people on ART decreases over time, from about $86 \%$ at 12 months to $72 \%$ at 60 months (WHO, 2013; Berheto et al., 2014). Albert Luthuli municipality is rated among the municipalities with highest HIV prevalence in South Africa but the predictors of LTFU after ART initiation are not wellinvestigated. Hence this study aimed to determine the prevalence and risk factors of LTFU in ART clinics in Albert Luthuli municipality of South Africa. 


\section{Methods}

\section{Study design and setting}

A cohort of HIV/AIDS patients was retrospectively followed from 2010 to 2017 until LTFU was diagnosed or until the end of the observation period at the two hospitals (Carolina and Embhuleni) in Albert Luthuli Local Municipality. This is a South African municipality situated in the Gert Sibande District of Mpumalanga Province. Carolina and Embhuleni district hospitals offer comprehensive health care services which include HIV/AIDS and tuberculosis (TB) treatments to the surrounding communities in Albert Luthuli municipality. These hospitals are accredited antiretroviral (ARV) treatment initiation and on-going treatment sites. Both Hospitals serve mostly the rural population in Albert Luthuli Municipality. The target population which was used as a sampling frame included all HIV/AIDS patients admitted and started ART treatment in the two hospitals within the three-month accrual period from the $1^{\text {st }}$ of January to the $31^{\text {st }}$ of March 2010. The variables which form part of the routine hospital records in Albert Luthuli municipality were used in this study and are described as follows. Loss to follow-up (LTFU) status is the dependent variable for the study. It was recorded in terms of LTFU status (yes, no) and time until its onset. The categorical independent variables were gender, hospital (Carolina, Embhuleni), WHO stage (1, 2, 3, 4), HIV disclosure (yes, no), marital status (single, married, cohabitation, widowed/divorced), treatments (regimen 1) $(\mathrm{NVP}+\mathrm{D} 4 \mathrm{~T}+3 \mathrm{TC}, \mathrm{EFV}+\mathrm{D} 4 \mathrm{~T}+3 \mathrm{TC}, \mathrm{EFV}+\mathrm{AZT}+3 \mathrm{TC}$, $\mathrm{EFV}+3 \mathrm{TC}+\mathrm{TDF}$ and $\mathrm{NVP}+3 \mathrm{TC}+\mathrm{TDF}$ ) and $\mathrm{ART}$ adherence (poor, fair, good). The continuous independent variables for the study except for age were classified into baseline and follow-up variables were mass, CD4 cell count, haemoglobin, lymphocyte, white blood cell count, viral load, creatinine, total protein, sodium and alanine transaminase. The cohort for this study was made up of children, adolescents and adults as in Moshago et al. (2014), however, it is recommended to have cohorts made up of participants with ages from 16 years and above as in most retrogressive follow-up studies. Diabetes and hypertension were excluded because their records were found in very few patient files. HIV/AIDS patients with missing essential records such as ART regimen, gender and date of birth or age were excluded from the study.

\section{Sample size and sampling procedure}

Sample size was determined by using sample size calculation formula for survival analysis by considering the following assumptions on HIV-infected patients: an average of $14.8 \%$ prevalence rate of LTFU among ART naïve patients (Seifu et al., 2018), 5\% precision or margin error, $95 \%$ 
level of confidence interval and 0.45 loss (Damtew et al., 2015). The sample size which was calculated using the formula $N=\frac{Z^{2} p(1-p)}{\alpha^{2}}$, (Eneyew et al., 2016), where $\mathrm{N}=$ sample size, $\mathrm{Z}=1.96$ (critical value at 95\% level of confidence), $\mathrm{p}=$ proportion of LTFU and $\alpha=$ type-1 error (0.05) was 357 . The estimated total sample size was proportionally and randomly allocated to the two study sites (Embhuleni and Carolina hospitals with proportions of $79 \%$ and $21 \%$ respectively) and according to the age and gender proportions.

\section{Ethical considerations}

The ethical approval for this study was granted by UNISA Ethics Review Committee with the approval number being 2017/SSR ERC/005. The permission to conduct the study at Carolina and Embhuleni hospitals was obtained from Mpumalanga Department of Health with the permission number being MP_201708_013. All data related to the patients were handled with utmost confidentiality in all the stages of the research. In addition, no reference to an individual respondent was made as all results were handled in aggregate format. The electronic documents carrying confidential information on patients are all protected by some encryption and will be destroyed as per research policy.

\section{Determination of loss to follow up status}

Loss to follow up was defined as not taking an ART refill for a period of 90 days or longer from the last attendance for refill and not yet classified as 'dead' or 'transferred-out' (Seifu et al., 2018). Patients who after meeting the criterion for LTFU came for refilling would be treated as patients attending the clinic for the first time.

\section{Statistical methods}

Johnson et al. (1994) proposed a four-parameter generalized gamma distribution which reduces to the generalized gamma distribution with three parameters defined by Stacy (1962) when the location parameter is set to zero. The generalized gamma distribution presents a flexible family with varying shapes and hazard functions which often are suitable for modelling survival data $(\mathrm{Yu}$, 2017; Kiche et al., 2019). The distribution of loss to follow up among HIV/AIDS patients were

modelled using the family of generalized gamma (GG) distribution. The GG distribution can be used to test the adequacy of commonly used Weibull, lognormal, gamma and exponential distributions, since they are all nested within the generalized gamma distribution family. A threeparameter generalized gamma probability density function is given by 


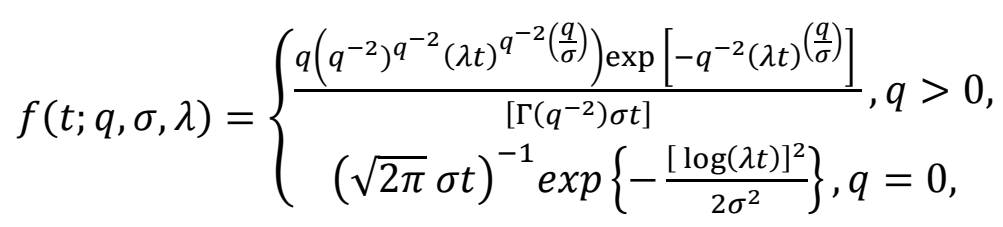

where $t>0$ is the lifetime, with $q \geq 0, \sigma>0$, and $\lambda>0$. Here, $\sigma$ and $q$ are the shape parameters and $\lambda$ is a scale parameter. $\Gamma($.$) represents the complete gamma function. The survival function$ corresponding to (1.1) is

$S(t ; \lambda, \sigma, q)=\left\{\begin{array}{l}\frac{\Gamma\left(q^{-2} \cdot q^{-2}(\lambda t)^{\frac{q}{\sigma}}\right)}{\Gamma\left(q^{-2}\right)}, q>0, \\ 1-\Phi\left(\frac{\log (\lambda t)}{\sigma}\right), q=0,\end{array}\right.$

where $\Gamma(a, b)=\int_{b}^{\infty} e^{-x} x^{a-1} d x$ is the upper incomplete gamma function and $\Phi($.$) is the$ cumulative distribution function of the standard normal distribution. The distribution (1.1) reduces to a Weibull distribution when $q=1$ to give the probability density function

$f_{w}(t)=(\lambda t)^{1 / \sigma} \exp \left[-(\lambda t)^{1 / \sigma}\right] / \sigma t$

The survival function corresponding to (1.3) is

$S_{w}(t)=\exp \left[-(\lambda t)^{1 / \sigma}\right]$

The hazard function $h(t)$ of a Weibull distribution function is given by $f_{w}(t) / S_{w}(t)$ which gives

$h(t)=\sigma \lambda^{\sigma} t^{\sigma-1}$

The distribution (1.1) reduces to a Lognormal distribution when $q=0$ to give the probability density function as 
$f_{l}(t)=(\sqrt{2 \pi} \sigma t)^{-1} \exp \left\{-\frac{[\log (\lambda t)]^{2}}{2 \sigma^{2}}\right\}$

and the corresponding survival function is

$S_{l}(t)=1-\Phi\left(\frac{\log (\lambda t)}{\sigma}\right)$

If $q / \sigma=1$ then the distribution (1.1) reduces to a gamma distribution

$f_{g}(t)=\sigma\left(\frac{\lambda t}{\sigma^{2}}\right)^{\sigma^{-2}} \exp \left[-(\lambda t) / \sigma^{2}\right] / \Gamma(t / \sigma)$

and the corresponding survival function is

$S_{g}(t)=\Gamma\left(1 / \sigma^{2},(\lambda t) / \sigma^{2}\right] / \Gamma\left(1 / \sigma^{2}\right)$

Lastly, if $q=\sigma=1$ then the distribution (1.1) reduces to an exponential distribution

$f_{e}(t)=\lambda \exp \{-\exp (\lambda t)\}$

and the corresponding survival function is

$S_{g}(t)=\Gamma(\lambda t)$

The generalized gamma family distributions described above were used to model the factors associated with LTFU. Akaike's Information Criterion (AIC), Corrected Akaike's Information Criterion (AICc), Bayesian Information Criterion (BIC) and log-likelihood were used as goodnessof-fit criteria for selecting the best model in modelling LTFU from survival data.

Let $0<t_{1}<t_{2}<t_{3}<\ldots<t_{k}<\infty$ be $k$ observed times to LTFU of patients during the observation period; $d_{i j}(i=1,2, \ldots, r ; j=1,2, \ldots, k)$ be the respective number of patients in the $i^{t h}$ group lost to follow-up at each of these times; and $n_{i j}$ be the corresponding number of remaining patients in the cohort at the respective times. Then Kaplan-Meier (KM) estimate of the survivor 
function $S_{i}(t)(i=1,2, \ldots, r)$ when times to LTFU of the patients in the $i^{\text {th }}$ group are tied is (Etikan et al., 2017)

$\hat{S}_{i}(t)=\prod_{j \mid t_{j} \leq t} 1-\left(\frac{d_{i j}}{n_{i j}}\right), i=1,2, \ldots, r$

In this study, the $r$ groups were the levels of the significant categorical covariates or categorized continuous covariates retained in the Cox regression analysis of LTFU. The log-rank test was used to test the null hypothesis (Etikan et al., 2017)

$H_{0}: S_{1}(t)=S_{2}(t)=\cdots=S_{r}(t) \equiv h_{1}(t)=h_{2}(t)=\cdots=h_{r}(t)$

for $t \geq 0$, where $h_{i}(t)$ is the hazard function of the $i^{\text {th }}$ group patients. Data for the study were recorded on research tools and then captured on microsoft excel database and checked against original records by two competent individuals.

Data was analysed using R Version 4.0.2. The main packages used were flexsurv, survfit and survival. The flexsurv is an $\mathrm{R}$ package for fully-parametric modelling of survival data and it provides functions for fitting and predicting from fully-parametric multi-state models (Jackson, 2016). The plot () method for 'flexsurvreg' objects which by default draws a Kaplan-Meier estimate of the survivor function $\mathrm{S}(\mathrm{t})$ is used as a quick check of model fit.

\section{Results}

\section{Exploratory data analysis}

Of the 357 patients, $60.5 \%$ were females. The mean (SD) age of the cohort was 36.2 (14.1), 15.4 (3.5), and 5.1 (3.5) years for adults, adolescents, and children, respectively. From 357 HIV/AIDS patients, 93 (26.05\%) were lost to follow-up. Table 1 shows the distribution of the patients lost to follow-up over the follow-up period of 7.5 years. Most patients got lost within the first year of initiation to ART. Loss to follow-up stabilized as from the end of $2^{\text {nd }}$ year until 4.5 years. As from 4.5 years until 7.5 years there were no new cases of LTFU. 
Table 1: The distribution of the patients lost to follow-up over the follow-up period

\begin{tabular}{|l|c|c|c|c|c|c|c|c|c|c|c|}
\hline Time (in years) & $\mathbf{0 . 5}$ & $\mathbf{1}$ & $\mathbf{1 . 5}$ & $\mathbf{2}$ & $\mathbf{2 . 5}$ & $\mathbf{3}$ & $\mathbf{3 . 5}$ & $\mathbf{4}$ & $\mathbf{4 . 5}$ & $\mathbf{\cdots}$ & $\mathbf{7 . 5}$ \\
\hline Number of patients lost & 29 & 20 & 15 & 12 & 3 & 2 & 3 & 5 & 4 & $\cdots$ & 0 \\
\hline \% of number lost & 31.18 & 21.51 & 16.13 & 12.90 & 3.23 & 2.15 & 3.23 & 5.38 & 4.3 & $\cdots$ & 0 \\
\hline Cumulative number lost & 29 & 49 & 64 & 76 & 79 & 81 & 84 & 89 & 93 & $\cdots$ & 93 \\
\hline $\begin{array}{l}\text { \% of cumulative number } \\
\text { lost }\end{array}$ & 31.18 & 52.69 & 68.13 & 81.72 & 84.95 & 87.1 & 90.33 & 95.71 & 100 & $\cdots$ & 100 \\
\hline
\end{tabular}

\section{Fitting the Weibull distribution}

The best fitting model was obtained by using the goodness-of-fit criteria as shown in Table 2 .

Table 2: Goodness of fit criteria for parametric distributions

\begin{tabular}{|l|l|l|l|l|}
\hline Parametric distribution & Weibull & $\begin{array}{l}\text { Generalized } \\
\text { Gamma }\end{array}$ & Lognormal & Exponential \\
\hline Goodness-of-fit criteria & & & & \\
\hline Akaike's Information Criterion & $\mathbf{1 6 0 0 . 8 8 6}$ & 1602.932 & 1607.171 & 1601.712 \\
\hline $\begin{array}{l}\text { Corrected Akaike's Information } \\
\text { Criterion }\end{array}$ & $\mathbf{1 6 0 2 . 1 1 4}$ & 1604.339 & 1608.399 & 1602.773 \\
\hline Bayesian Information Criterion & 1655.174 & $\mathbf{1 6 6 1 . 0 9 8}$ & 1661.459 & $\mathbf{1 6 5 2 . 1 2 3}$ \\
\hline Log-likelihood & $\mathbf{- 7 8 6 . 4 4 3 1}$ & -786.4659 & -789.5854 & -787.856 \\
\hline
\end{tabular}

Table 2 shows AIC, AICc, BIC and log likelihood statistics for the four parametric models which were applied to the survival data. These goodness of fit criteria were used to select the best fitting parametric model. According to these criteria, the Weibull model achieved the lowest AIC, AICc and log likelihood values and was therefore the best model for predicting LTFU among HIV/AIDS patients on ART.

Table 3 shows the results that were obtained from the fitted Weibull model. The significant factors which were found to be positively associated with LTFU at 0.05 are: regimen $\mathrm{EFV}+\mathrm{D} 4 \mathrm{~T}+3 \mathrm{TC}$ [HR: $2.0 \mathrm{CI} ;(1.3-3.1)]$, regimen $\mathrm{EFV}+\mathrm{AZT}+3 \mathrm{TC} \quad[\mathrm{HR}: 2.9 \mathrm{CI} ;(1.3-6.4)]$, regimen EFV+3TC+TDF [HR: 10.0 CI;(3.9-25.9)], regimen NVP+3TC+TDF [HR: 10.6 CI;(1.8-62.4)], 
follow up CD4 [HR: $1.0 \mathrm{CI} ;(1.0-1.0)$ ], ART adherence (fair) [HR: $2.4 \mathrm{CI} ;(1.3-3.4)$ ], ART adherence (good) [HR: 4.6 CI;(2.2-9.5)] and age [HR: $1.02 \mathrm{CI} ;(1.0-1.04)]$. On the other hand, the significant factors which were found to be negatively associated with LTFU at 0.05 level are: $\log$ (follow up viral load) [HR: $0.8 \mathrm{CI} ;(0.7-0.9)$ ], marital status (married) [HR: $0.4 \mathrm{CI} ;(0.3-0.8)$ ] and marital status (cohabitation) [HR: $0.6 \mathrm{CI} ;(0.3-0.9)]$.

Table 3: The estimates of the Weibull distribution

\begin{tabular}{|c|c|c|c|c|c|c|c|c|}
\hline Estimates & $\begin{array}{l}\text { Data } \\
\text { mean }\end{array}$ & est & L95\% & U95\% & se & $\exp ($ est $)$ & L95\% & U95\% \\
\hline shape & NA & 1.15 & 0.983 & 1.36 & 0.095 & NA & $\mathrm{NA}$ & NA \\
\hline scale & $\mathrm{NA}$ & 882 & 289 & 2700 & 503 & NA & $\mathrm{NA}$ & $\mathrm{NA}$ \\
\hline ART:EFV+D4T+3TC & 0.49 & 0.7070 & 0.2870 & 1.1300 & 0.2140 & 2.0300 & 1.3300 & 3.0800 \\
\hline ART:EFV+AZT+3TC & 0.0728 & 1.0500 & 0.2580 & 1.8500 & 0.4060 & 2.8700 & 1.2900 & 6.3500 \\
\hline ART: EFV+3TC+TDF & 0.1340 & 2.3100 & 1.3600 & 3.2500 & 0.4840 & 10.000 & 3.8800 & 25.900 \\
\hline ART: NVP+3TC+TDF & 0.0560 & 2.3600 & 0.5930 & 4.1300 & 0.9030 & 10.600 & 1.8100 & 62.400 \\
\hline Fair ART adherence & 0.6550 & 0.8560 & 0.4200 & 1.2900 & 0.2230 & 2.3500 & 1.5200 & 3.6400 \\
\hline Good ART adherence & 0.1320 & 1.5200 & 0.7880 & 2.2500 & 0.3740 & 4.5700 & 2.2000 & 9.5200 \\
\hline Follow-up CD4 & 309 & 0.0012 & 0.0001 & 0.0023 & 0.0006 & 1.000 & 1.000 & 1.000 \\
\hline logFollow-up viral load & 4.100 & -0.2150 & -0.360 & -0.0699 & 0.0741 & 0.8060 & 0.697 & 0.932 \\
\hline Status:Married & 0.2610 & -0.8210 & -1.3700 & -0.2680 & 0.2820 & 0.440 & 0.253 & 0.765 \\
\hline Status:Cohabitation & 0.2720 & -0.5950 & -1.0900 & -0.100 & 0.2520 & 0.552 & 0.337 & 0.905 \\
\hline Status:Divorced/Widowed & 0.0420 & -0.5170 & -1.8400 & 0.8090 & 0.6770 & 0.5960 & 0.1580 & 2.250 \\
\hline Age & 32.3 & 0.0200 & 0.0007 & 0.0393 & 0.0098 & 1.0200 & 1.000 & 1.040 \\
\hline
\end{tabular}

Key: Reference levels: 'NVP+D4T+3TC' for Treatment (Regimen 1); 'Poor' for ART adherence, 'Single' for marital status

Table 3 shows the main effects which are associated with LTFU. The description which follows for each covariate, assumes that other covariates are held constant. The ART regimens $\mathrm{EFV}+\mathrm{D} 4 \mathrm{~T}+3 \mathrm{TC}$ and $\mathrm{EFV}+\mathrm{AZT}+3 \mathrm{TC}$ relative to $\mathrm{NVP}+\mathrm{D} 4 \mathrm{~T}+3 \mathrm{TC}$, each has an effect of increasing the hazard to LTFU by about 2 times and 3 times respectively. On the other hand, the ART regimens $\mathrm{EFV}+3 \mathrm{TC}+\mathrm{TDF}$ and $\mathrm{NVP}+3 \mathrm{TC}+\mathrm{TDF}$ relative to $\mathrm{NVP}+\mathrm{D} 4 \mathrm{~T}+3 \mathrm{TC}$, each has an effect of increasing the hazard to LTFU by about 10 times and 11 times respectively. Good and Fair ART adherence relative to poor ART adherence, each has the effect of increasing the hazard to LTFU by about 5 times and 2 times respectively. This effect is unexpected. Although follow- 
up CD4 is positively associated with LTFU and clinically significant, it does not have a statistical impact on LTFU. An increase in follow-up viral load among the patients has the effect of decreasing the hazard to LTFU by about $20 \%$, and this effect can be as low as $30 \%$ to $7 \%$. Being married and being in cohabitation relative to being single, each has the effect of decreasing the hazard to LTFU by about 0.4 times and 0.6 times respectively. Lastly, an increase in the age of a patient by one year has the effect of increasing the hazard to LTFU by about 1.02 times, and this effect can be as high as 1.04 times to 1 times.

\section{Nonparametric inferences about the survivor functions}

The cohort of HIV+ terminal patients in this study is not homogeneous with respect to their characteristics that may affect their survival from LTFU. Hence, it will be necessary to test the equality of survivor functions among groups (strata) of patients. The function 'survdiff()' was used to test for the differences in survival between two groups using a log-rank test. Log-rank tests and the Kaplan-Meier functions presented in this section are for ART treatments, ART adherence, Follow-up CD4, Follow-up viral load, Marital status and age.

The parametric plots for all modelled covariates (figure 1 to figure 6) approximate K-M plots meticulously for high LTFU survival probabilities (above 50\%), while for low LTFU survival probabilities (below 50\%), all the three parametric plots ( Weibull, Exponential and Generalized gamma) deviate significantly from the associated K-M plots. In addition, the Weibull plots for all the modelled covariates approximate the K-M plots better than Exponential and Generalized gamma distributions.

\section{Kaplan-Meier survival functions}

The K-M plot (Figure 1) shows that regimens EFV+3TC+TDF and NVP+3TC+TDF are associated with higher probability of LTFU than EFV+D4T $+3 \mathrm{TC}$ and EFV $+\mathrm{AZT}+3 \mathrm{TC}$ whose survival probabilities from LTFU are above $90 \%$. The treatment groups are significantly different as the log rank p-value is less than 0.05 . The marital status groups as shown in figure 2 are significantly different as depicted by the log rank p-value (0.0014). 
Figure 1: Kaplan Meier and parametric plots for estimated probabilities for the association between treatment regimen and loss to follow-up

Married and cohabitating patients relative to single patients survive LTFU better.

Figure 2: Kaplan Meier and parametric plots for estimated probabilities for the association between marital status and loss to follow-up

As shown in Figure 3, patients with good or fair ART adherence are more likely to get lost to follow-up than patients with poor ART adherence.

Figure 3: Kaplan Meier and parametric plots for estimated probabilities for the association between ART adherence and loss to follow-up

The groups of patients according to ART adherence are statistically different (log rank p-value $=0.0000)$.

CD4 and viral load were categorised as done in the standard Laboratory report in South African hospitals. Figure 4 shows that survivor functions for Follow-up viral load are statistically different at 0.05 significance level (log rank p-value $=0.0000)$ and this confirms that Follow-up viral load strata are associated with LTFU hazard.

Figure 4: Kaplan Meier and parametric plots for estimated probabilities for the association between viral load and loss to follow-up

Figure 5 shows that survivor functions for Follow-up CD4 are statistically different at 0.05 significance level $(\log$ rank p-value $=0.0000)$ and this confirms that CD4 strata are associated with LTFU hazard.

Figure 5: Kaplan Meier and parametric plots for estimated probabilities for the association between CD4 count and loss to follow-up

Lastly, in Figure 6, the survivor functions for Age are marginally not statistically different at 0.05 significance level $(\log$ rank $p$-value $=0.0576)$ and this confirms that Age strata are statistically marginally not associated with LTFU hazard.

Figure 6: Kaplan Meier and parametric plots for estimated probabilities for the association between age group and loss to follow-up 


\section{Discussion}

This research has several strengths. Firstly, research follow-up time of 7.5 years is relatively long to yield consistent records and hence reliable findings. Secondly, the research has diverse covariates with most of them having paired baseline and follow-up covariates for exhaustive comparisons of associations. Finally, this was not a single-centre study, it involved two district hospitals namely Embhuleni and Carolina for comparison and for completeness in coverage.

The prevalence of LTFU in this study concurs with studies in Nigeria, Ethiopia and Zimbabwe wherein Aliyu et al. (2019), Berheto et al. (2014) and Zingoni et al. (2020) found the LTFU prevalence of $30.6 \%, 26.7 \%$ and $22.7 \%$ respectively. However, Seifu et al. (2018) found the prevalence of LTFU in Ethiopia as $14.8 \%$. The difference in prevalence findings could be explained by study design, population variation, variables considered and the clinical definition for LTFU.

As shown in Figure 3, patients with good or fair ART adherence are unexpectedly more likely to get lost to follow-up than patients with poor ART adherence. The implication is that patients who fully adhere to the use of ART drugs are the once who are more likely to get lost to follow-up. Could this be the case, then the highly probable culprit drugs could be EFV+3TC+TDF and NVP+3TC+TDF as shown in Figure 1. As shown in Figure 6, patients in the age group 10-20 years are more likely to get lost to follow-up than patients in other age groups. These findings concur with the findings by Brinkhof et al. (2009) and Berheto et al. (2014) who found out that younger age and adverse drug reactions are among the predictors of LTFU of HIV+ patients on ART treatment. The association of EFV+3TC+TDF and NVP+3TC+TDF with high levels of LTFU as in Figure 1 could be resulting from nephrotoxicity. According to Boswell and Rossouw (2017), Wyatt (2015) and Kalayjian et al. (2012), TDF-containing regimens have been found to have the potential to cause nephrotoxicity and hence to significantly contribute to CKD among HIVinfected patients.

Lastly, Nakhaee and Law (2011) used four parametric survival models (exponential, Weibull, lognormal and log-logistic) for survival analysis of HIV/AIDS patients in Australia, and the Weibull 
model just as in this study, was found to be the best parametric model. Although the Cox model is frequently used in survival analysis, parametric models may fit data better and give more precise estimates of the quantities of interest (Hamidi et al., 2017).

\section{Conclusion}

Patients with increased risk for LTFU were consistent with ART regimens, viral load, age, CD4 count, adherence and marital status. The identification of the patients at risk to LTFU at an early stage helps in putting control mechanisms in place before LTFU goes out of hand. Stringent measures are supposed to be employed to curtail LTFU, especially during this COVID-19 pandemic period.

\section{Acknowledgement}


We are grateful to HIV/AIDS clinics staff for Carolina and Embhuleni hospitals. The Data capturers assisted with data collection while the administrative staff swiftly performed data collection permissions protocols.

\section{Author information}

Author notes

Pepukai Bengura contributed to this work.

\section{Author's contributions}

PB was involved in obtaining ethics approval, data collection/analysis and drafting of the manuscript, data interpretation, project design and editing the manuscript.

\section{Corresponding author}

Correspondence to Pepukai Bengura.

\section{Funding}

Not applicable.

\section{Ethics declarations}

\section{Ethics approval and consent to participate}

This study was conducted in accordance with the South African local and national research guidelines. Ethics approval for this project was obtained from UNISA Ethics Review Committee (ERC) with the approval number being (2017/SSR ERC/005). The permission to conduct the study at Carolina and Embhuleni hospitals was obtained from Mpumalanga Department of Health with the permission number being (MP_201708_013). The consent to participate does not apply to a patient since no reference to an individual respondent was made, all results were handled in aggregate format.

\section{Availability of data and materials}

The data that support the findings of this study are available from the Department of health, but restrictions apply to the availability of these data, and so are not publicly available. Data are however available from the author upon reasonable request and with permission of the Department of health.

\section{Consent for publication}

Not applicable. 


\section{Competing interests}

The author declares no competing interests.

\section{Author details}

Department of Statistics, University of South Africa, Pretoria. 


\section{References}

1. UNAIDS. Fact sheet_world AIDS day 2020, Global HIV statistics, 2020.

https://www.unaids.org/en/resources/fact-sheet

2. Avert. Global information and education on HIV and AIDS: HIV and AIDS in South Africa. 2018. https:/www.avert.org/professionals/hiv-around-world/sub-saharan-africa/south africa

3. Motsoaledi, A. Mpumalanga's Gert Sibande district has highest HIV rate. City Press. (2013, November 22). http://www.news24.com/Archives/City-Press/Mpumalangas-Gert-Sibande

4. Nkosi, J. Chief Albert Luthuli local municipality Integrated Development Plan (IDP) 20172022. 2017. Caroline. Mpumalanga. Chief Albert Luthuli Local Municipality

5. WHO. Technical report. Access to Antiretroviral drugs in Low-and Middle income countries. 2014. https://apps.who.int/iris/bitstream/10665/128150/1/9789241507547_eng.pdf.

6. Kaplan JE, Hanson D, Dworkin MS, Frederick T, Bertolli J, Lindegren ML, Holmberg S, and Jones JL. Epidemiology of Human Immunodeficiency Virus-Associated Opportunistic Infections in the United States in the Era of Highly Active Antiretroviral Therapy. Clinical Infectious Diseases, 2000; 30:S5-14. https://academic.oup.com/cid/article/30/Supplement 1/S5/393485

7. Taiwo B. Understanding transmitted HIV resistance through the experience in the USA. International Journal of Infectious Diseases, 2009; 13, 552-559 doi:10.1016/j.ijid.2008.10.008

8. Chammartin F, Zürcher K, Keiser O, Weigel R, Chu K, Kiragga AN, Ardura-Garcia C, Anderegg N, Laurent C, Cornell M, Tweya H, Haas AD, Rice BD, Geng EH, Fox MP, Hargreaves JR and Egger M. Outcomes of Patients Lost to Follow-up in African Antiretroviral Therapy Programs: Individual Patient Data Meta-analysis. Clinical Infectious Diseases, 2018; 67(11):1643-52. DOI: 10.1093/cid/ciy347

9. Brinkhof MWG, Pujades-Rodriguez M and Egger M. Mortality of Patients Lost to Follow-Up in Antiretroviral Treatment Programmes in Resource-

Limited Settings: Systematic Review and Meta-Analysis. PLoS ONE, 2009; 4(6): e5790. doi:10.1371/journal.pone.0005790 
10. Berheto TM, Haile DB and Mohammed S. Predictors of Loss to follow-up in Patients Living with HIV/AIDS after Initiation of Antiretroviral Therapy. North American Journal of Medical Sciences, 2014; 6 (9). DOI:10.4103/1947-2714.141636

11. De La Mata NL, Ly PS, Nguyen KV, Merati TP, Pham TT, Lee MP, Choi JY, Ross J, Law MG, and Ng OT. Loss to follow-up trends in HIV-positive patients receiving antiretroviral treatment in Asia from 2003 to 2013. J Acquir Immune Defic Syndr, 2017; 74(5): 555-562. doi:10.1097/QAI.0000000000001293.

12. McManus H, Petoumenos K, Brown K, Baker D, Russell D, Read T, Smith D, Wray L, Giles M, Hoy J, Carr A, Law M, and the Australian HIV Observational Database. Loss to follow-up in the Australian HIV Observational Database. Antivir Ther, 2015; 20(7): 731-741.

doi:10.3851/IMP2916.

13. Geng EH, Odeny TA, Lyamuya R, Nakiwogga-Muwanga A, Diero L, Bwana M, Braitstein P, Somi G, Kambugu A, Bukusi E, Wenger M, Neilands TB, Glidden DV, Wools-Kaloustian K, Yiannoutsos C and Martin J. Retention in Care and Patient-Reported Reasons for Undocumented Transfer or Stopping Care Among HIV-Infected Patients on Antiretroviral Therapy in Eastern Africa: Application of a Sampling-Based Approach. Clinical Infectious Diseases, 2016; 62(7):935-44. DOI: 10.1093/cid/civ1004

14. Moshago T, Haile D and Enkusilasie F. Survival Analysis of HIV Infected People on Antiretroviral Therapy at Mizan-Aman General Hospital, Southwest Ethiopia. International Journal of Science and Research (IJSR), 2014; 3(5). http://www.ijsr.net/archive/v3i5/MDIwMTMyMTAz.pdf

15. Seifu W, Ali W and Meresa B. Predictors of loss to follow up among adult clients attending antiretroviral treatment at Karamara general hospital, Jigjiga town, Eastern Ethiopia, 2015: a retrospective cohort study. BMC Infectious Diseases, 2018; 18(280) https://doi.org/10.1186/s12879-018-3188-4

16. Damtew B, Mengistie B, and Alemayehu T. Survival and determinants of mortality in adult HIV/Aids patients initiating antiretroviral therapy in Somali Region, Eastern Ethiopia. Pan African Medical Journal, 2015; 22(138). doi: 10.11604/pamj.2015.22.138.4352

17. Eneyew K, Seifu D, Amogne W, and Menon M. Assessment of Renal Function among HIVInfected Patients on Combination Antiretroviral Therapy at Tikur Anbessa Specialized Hospital, Addis Ababa, Ethiopia. Technology and Investment, 2016; 7, 107-122. doi: 10.4236/ti.2016.73013 
18. Johnson NL, Kotz S and Balakrishnan N. Continuous Univariate Distributions, 1994; Vol. 1, 2nd edition, Wiley and Sons, Inc., New York.

19. Stacy EW. A generalization of the gamma distribution. Annals of Mathematical Statistics, 1962; 33 (3), 1187-1192. https://projecteuclid.org/euclid.aoms/1177704481

20. Yu H. Use of generalized gamma distribution in modelling lifetime data. The University of Texas at Arlington. Master of Science in Mathematics thesis, 2017. https://rc.library.uta.edu/utair/bitstream/handle/10106/26769/YU-THESIS-2017.pdf?sequence=1\&isAllowed=y.

21. Kiche J, Ngesa O and Orwa G. On Generalized Gamma Distribution and Its Application to Survival Data. International Journal of Statistics and Probability, 2019; 8(5). doi:10.5539/ijsp.v8n5p85

22. Etikan I, Abubakar S and Alkassim R. The Kaplan Meier Estimate in Survival Analysis. Biom Biostat Int J, 2017; 5(2): 00128. http://medcraveonline.com/BBIJ/BBIJ-05-00128.php

23. Jackson C. flexsurv: A Platform for Parametric Survival Modeling in R. Journal of Statistical Software, 2016; 70(8). doi: 10.18637/jss.v070.i08

24. Aliyu A, Adelekan B, Andrew N, Ekong E, Dapiap S, Murtala-Ibrahim F, Nta I, Ndembi N, Mensah C and Dakum P. Predictors of loss to follow-up in art experienced patients in Nigeria: a 13 year review (2004-2017). AIDS Res Ther, 2019; 16(30). https://doi.org/10.1186/s12981-019$0241-3$

25. Zingoni ZM, Chirwa T, Todd J and Musenge E. Competing risk of mortality on loss to follow-up outcome among patients with HIV on ART: a retrospective cohort study from the Zimbabwe national ART programme. BMJ Open, 2020; 10:e036136. doi:10.1136/ bmjopen-2019-036136

26. Boswell MT and Rossouw TM. Approach to acute kidney injury in HIV-infected patients in South Africa. South Africa: Southern African Journal of HIV Medicine, 2017. doi:https://doi.org/10.4102/

27. Wyatt CM. Kidney Disease and HIV Infection. Top Antivir Med, 2017;25(1):13-6. https://www.ncbi.nlm.nih.gov/pmc/articles/PMC5677039/.

28. Kalayjian RC, Lau B, Mechekano RN, Crane HM, Rodriguez B, Salata RA, Krishnasami Z, Willig JH, Martin JN, Moore RD, Eron JJ and Kitahata MM. Risk factors for chronic kidney disease in a large cohort of HIV-1 infected individuals initiating antiretroviral therapy in routine care. AIDS, 2012 Sep 24; 26(15):1907-15. https://www.ncbi.nlm.nih.gov/pubmed/22824630. Accessed 18 Dec 2018. 
29. Nakhaee F and Law M. Parametric modelling of survival following HIV and AIDS in the era of highly active antiretroviral therapy: data from Australia. Eastern Mediterranean Health Journal,2011;17(3).

https://pdfs.semanticscholar.org/0046/d27a30da17665b5075263cd2b62b952206ae.pdf

30. Hamidi O, Poorolajal J, and Tapak L. Identifying predictors of progression to AIDS and mortality post-HIV infection using parametric multistate model. Epidemiology Biostatistics and Public Health, 2017; 14(2). DOI: 10.2427/12438 


\section{Figures}
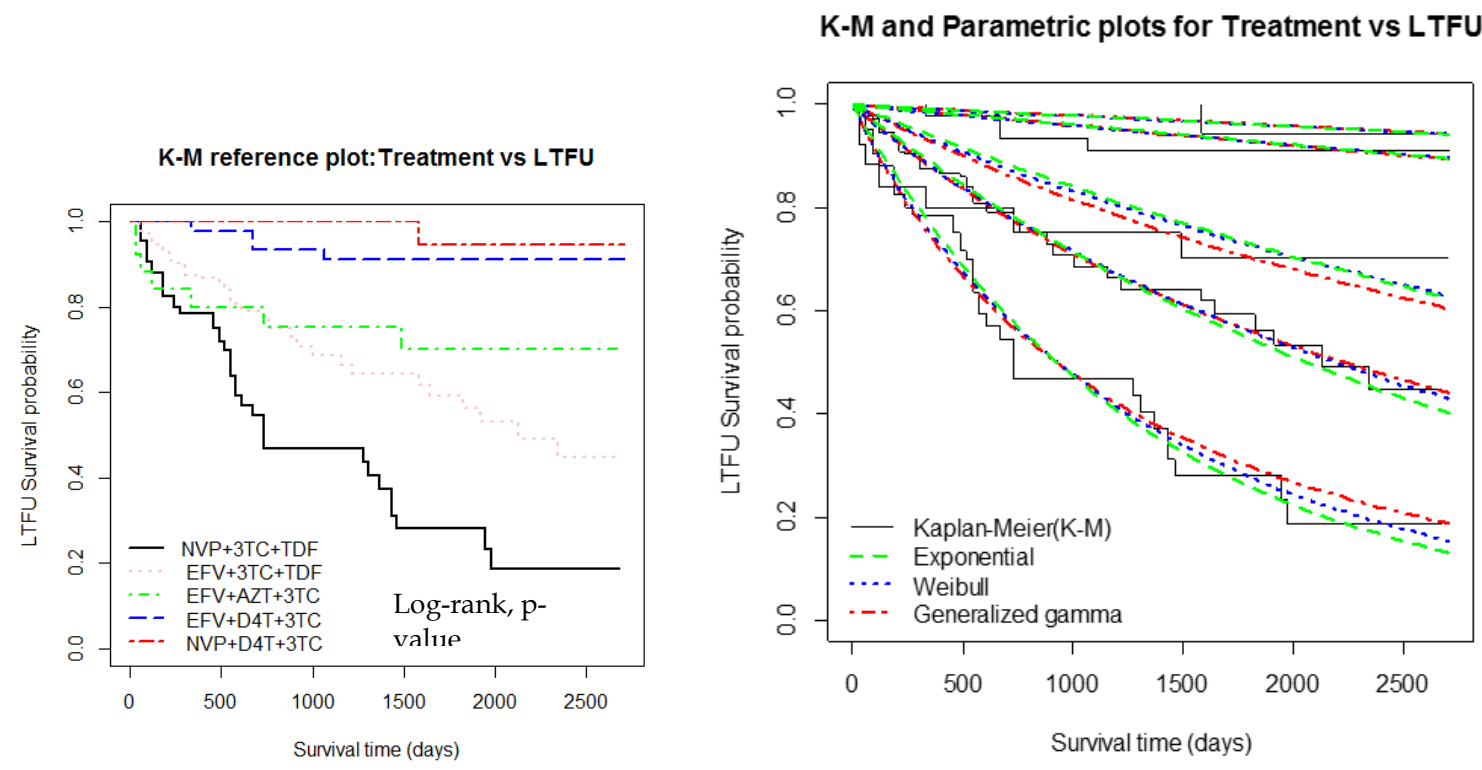

Figure 1: Kaplan Meier and parametric plots for estimated probabilities for the association between treatment regimen and loss to follow-up

K-M and Parametric plots for Marital status vs LTFU

K-M reference plot Marital status vs LTFU

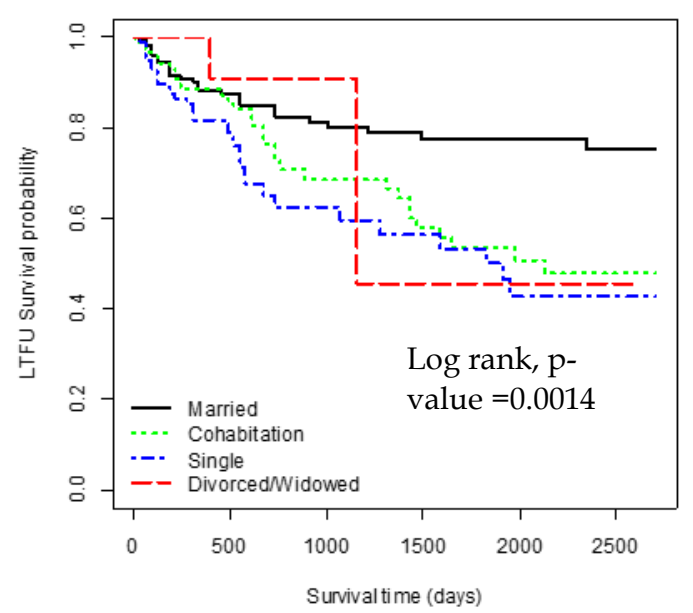

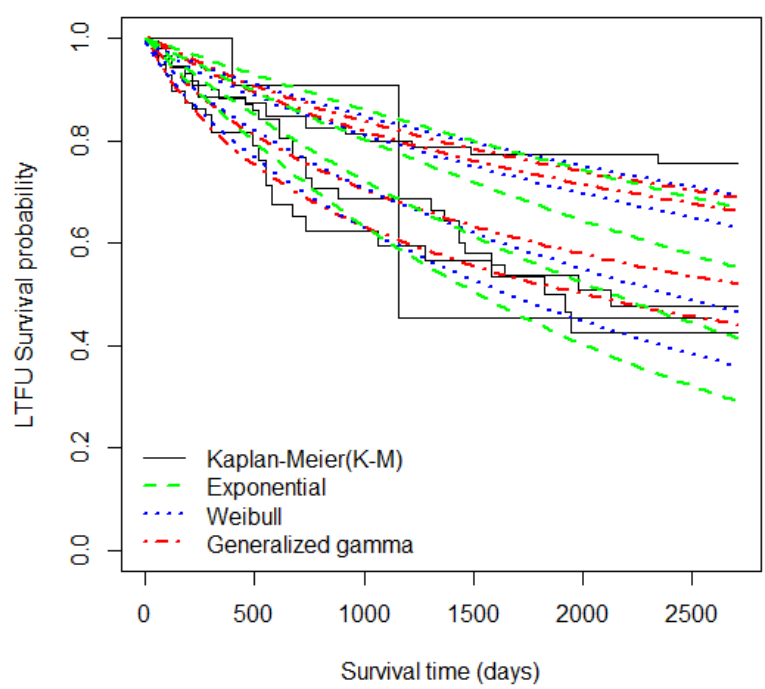

Survival time (days)

Figure 2: Kaplan Meier and parametric plots for estimated probabilities for the association between marital status and loss to follow-up 

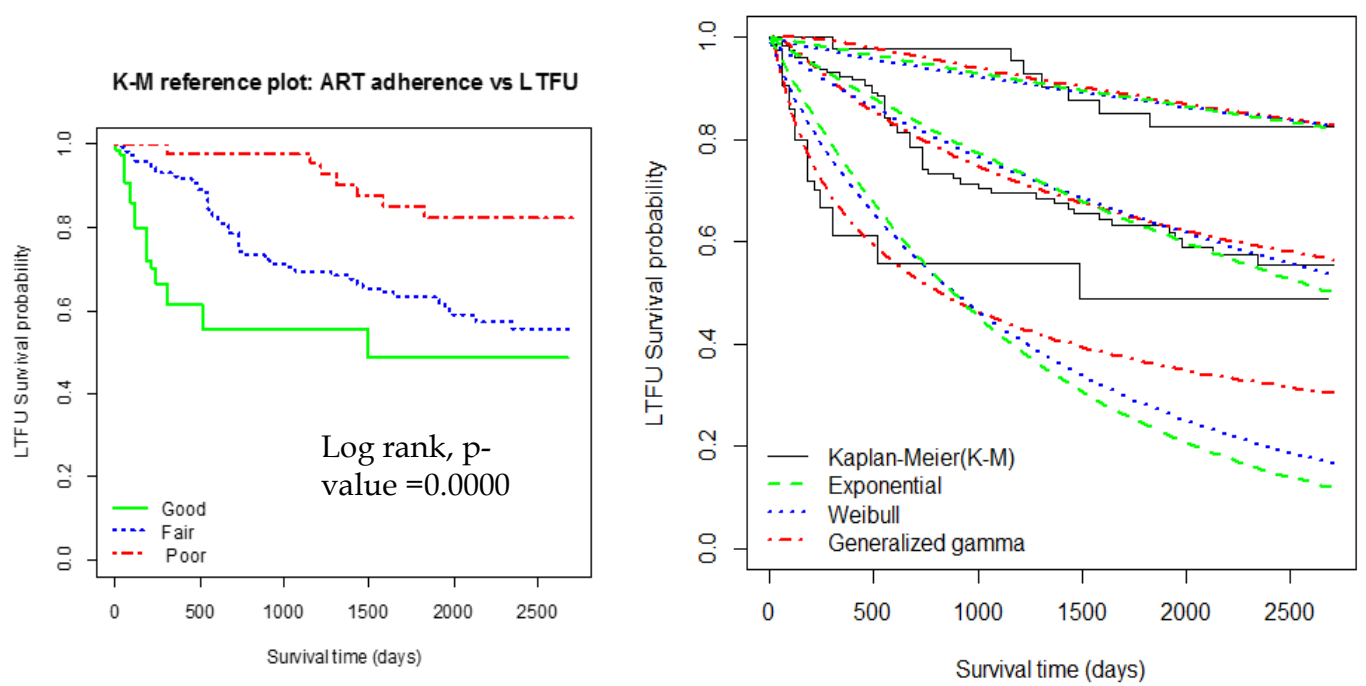

Figure 3: Kaplan Meier and parametric plots for estimated probabilities for the association between ART adherence and loss to follow-up

K-M and Parametric plots for Viral load vs LTFU
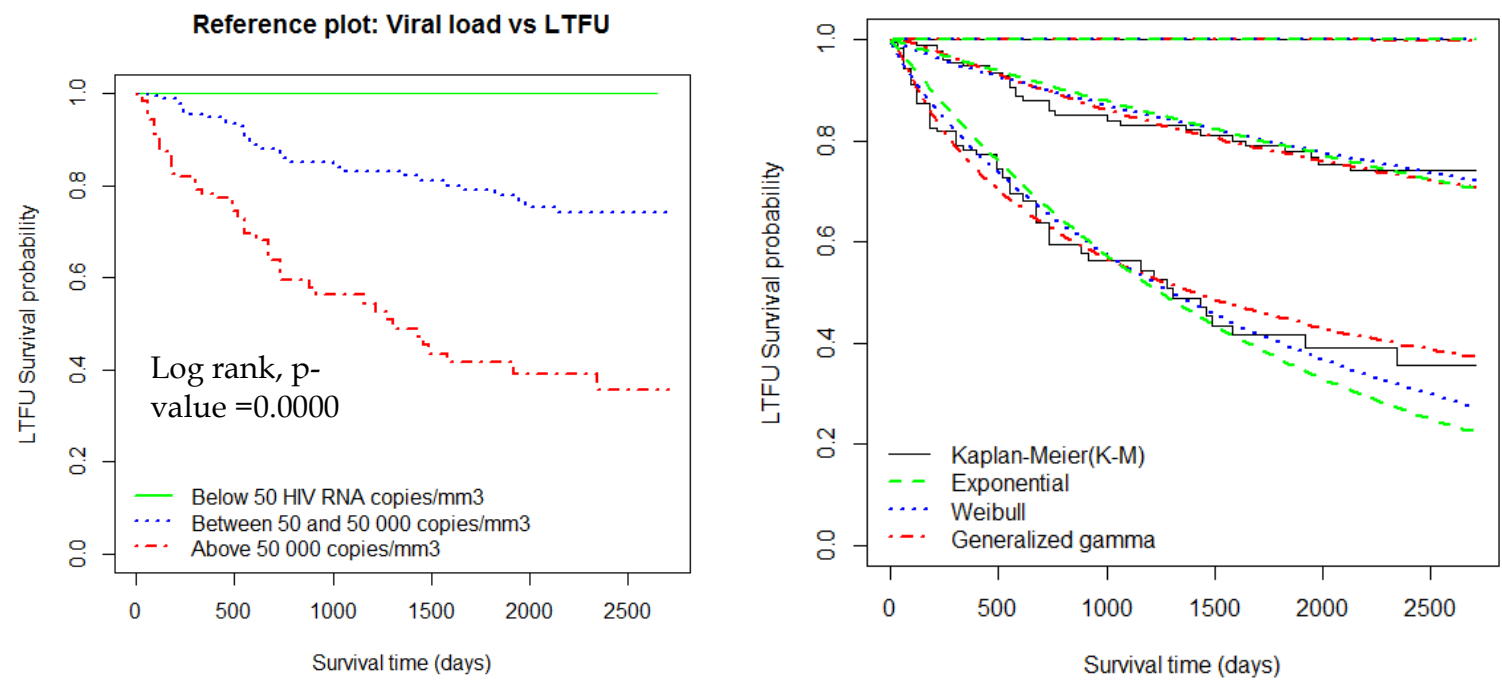

Figure 4: Kaplan Meier and parametric plots for estimated probabilities for the association between viral load and loss to follow-up 

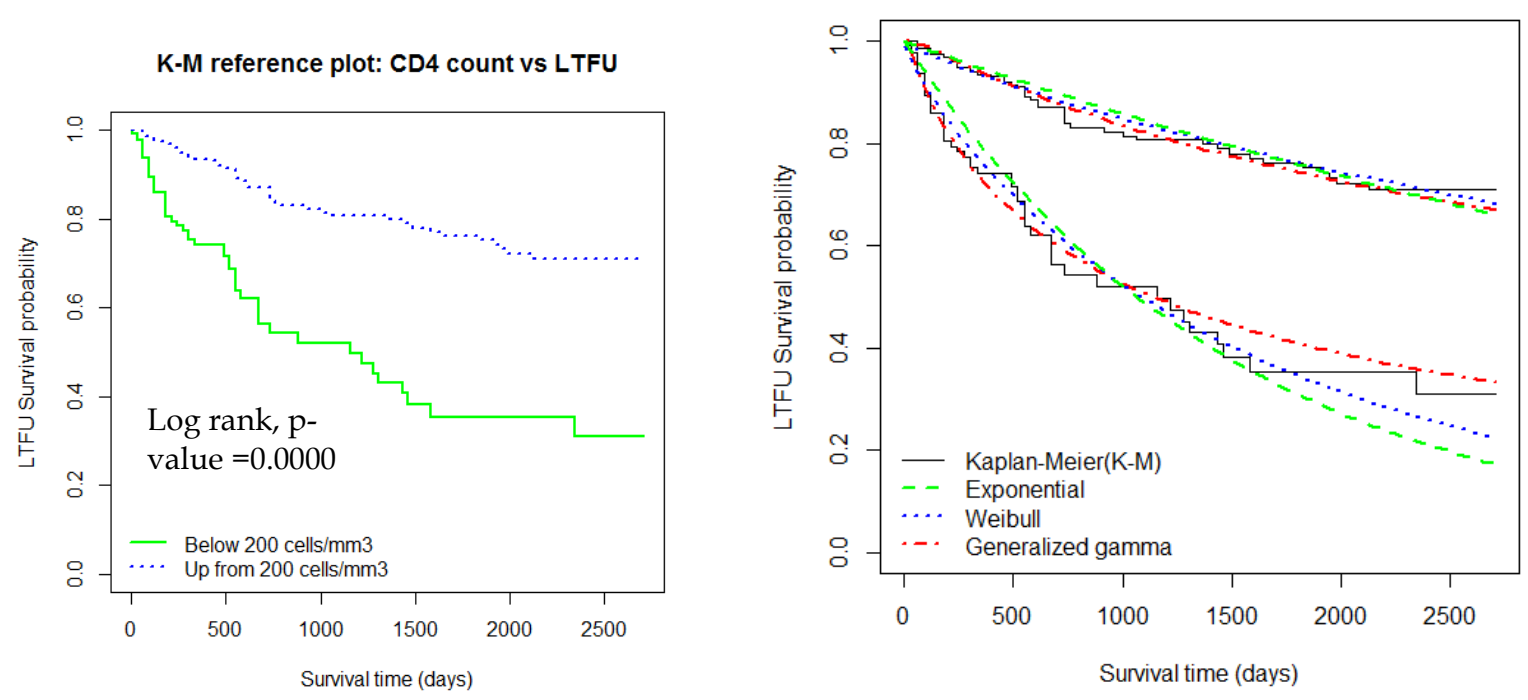

Figure 5: Kaplan Meier and parametric plots for estimated probabilities for the association between CD4 count and loss to follow-up

K-M and Parametric plots for Age group vs LTFU
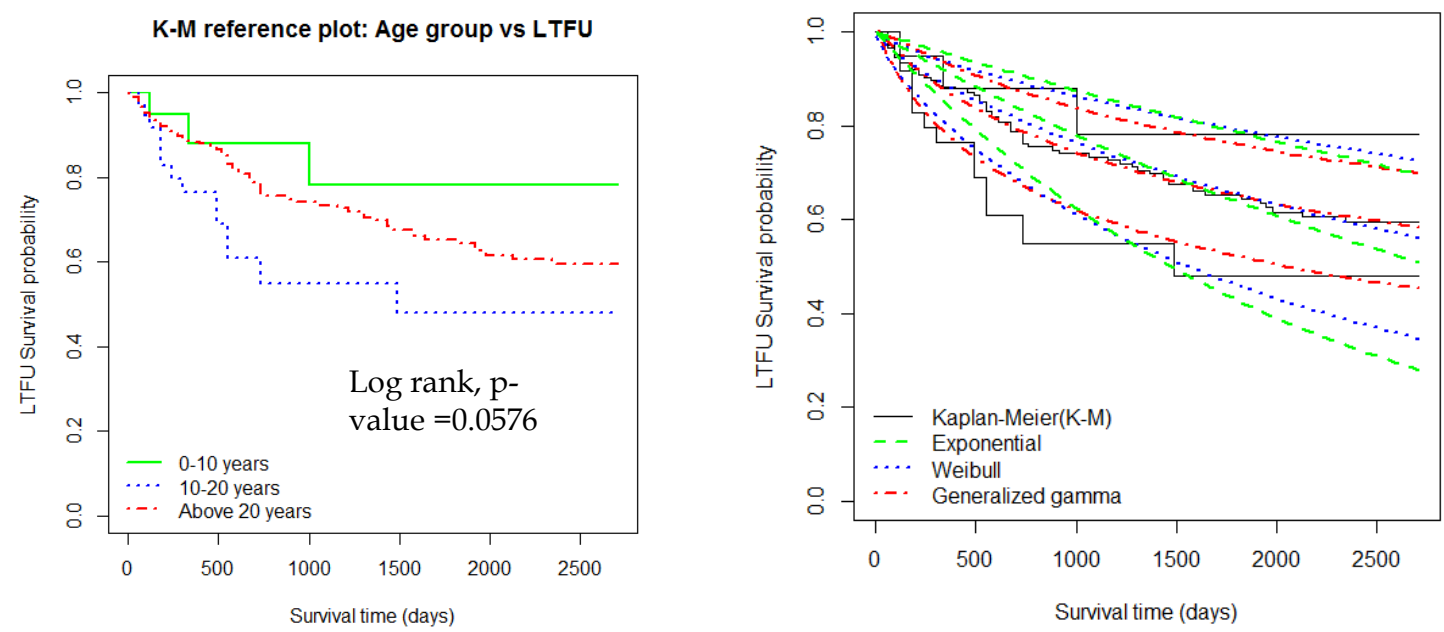

Figure 6: Kaplan Meier and parametric plots for estimated probabilities for the association between age group and loss to follow-up 


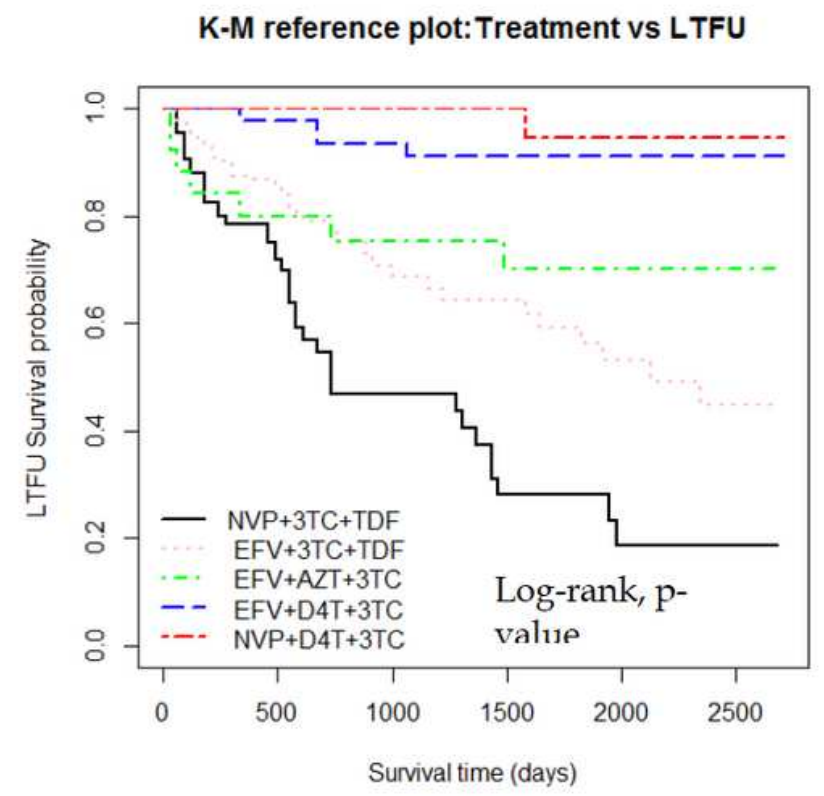

Figure 1

Kaplan Meier and parametric plots for estimated probabilities for the association between treatment regimen and loss to follow up

K-M and Parametric plots for Marital status vs LTFU

K-M reference plot Marital status vs LTFU

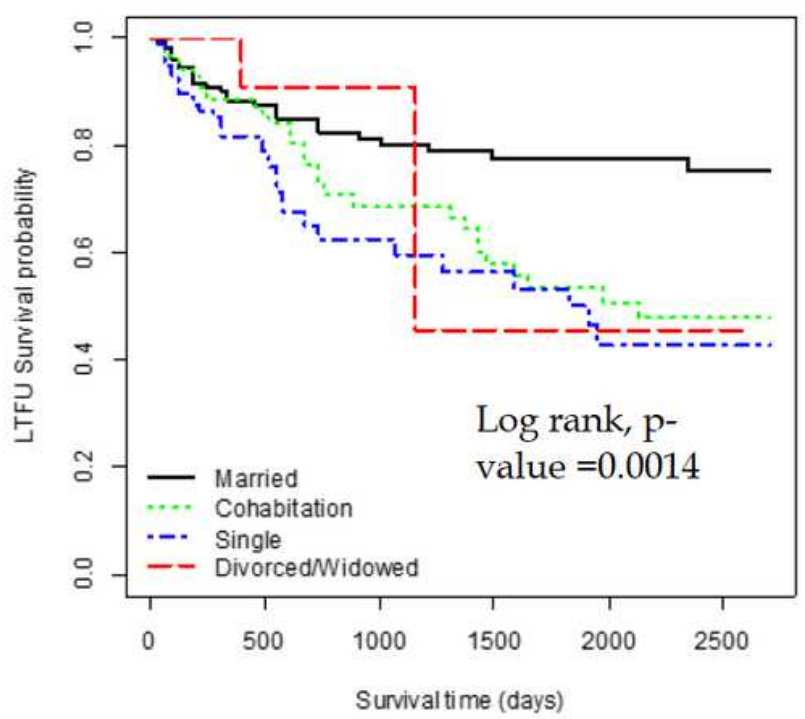

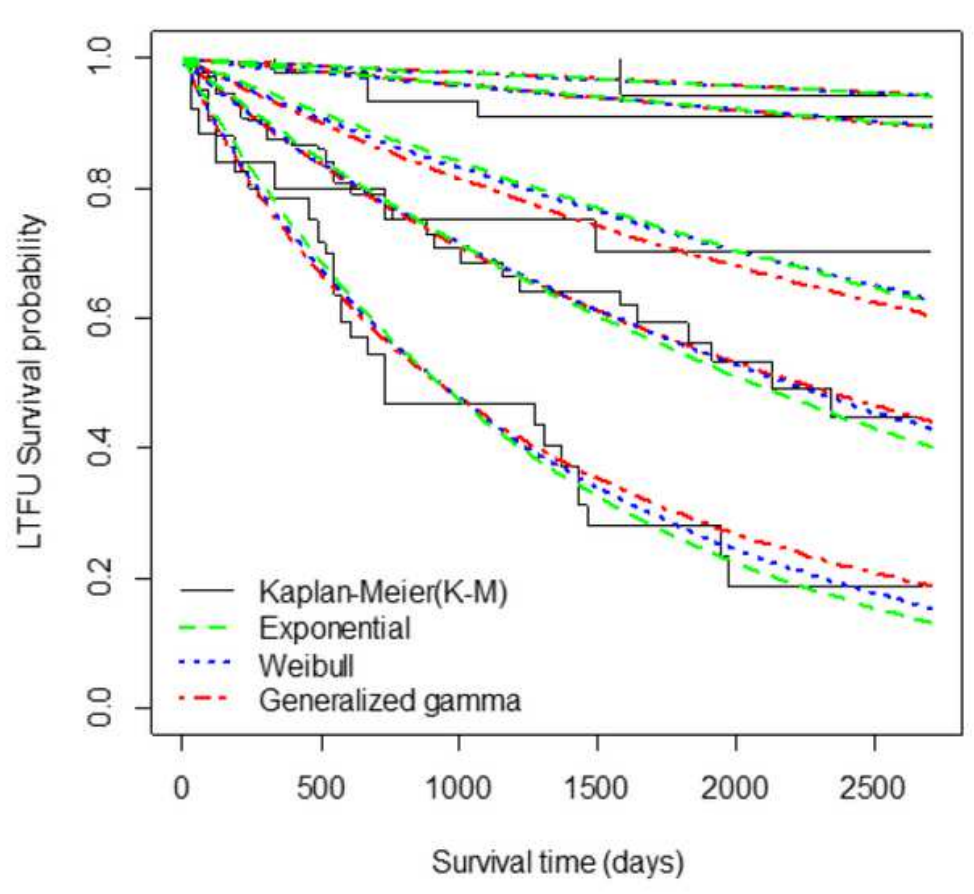

K-M and Parametric plots for Treatment vs LTFU 
Figure 2

Kaplan Meier and parametric plots for estimate $d$ probabilities for the association between marital status and loss to follow up

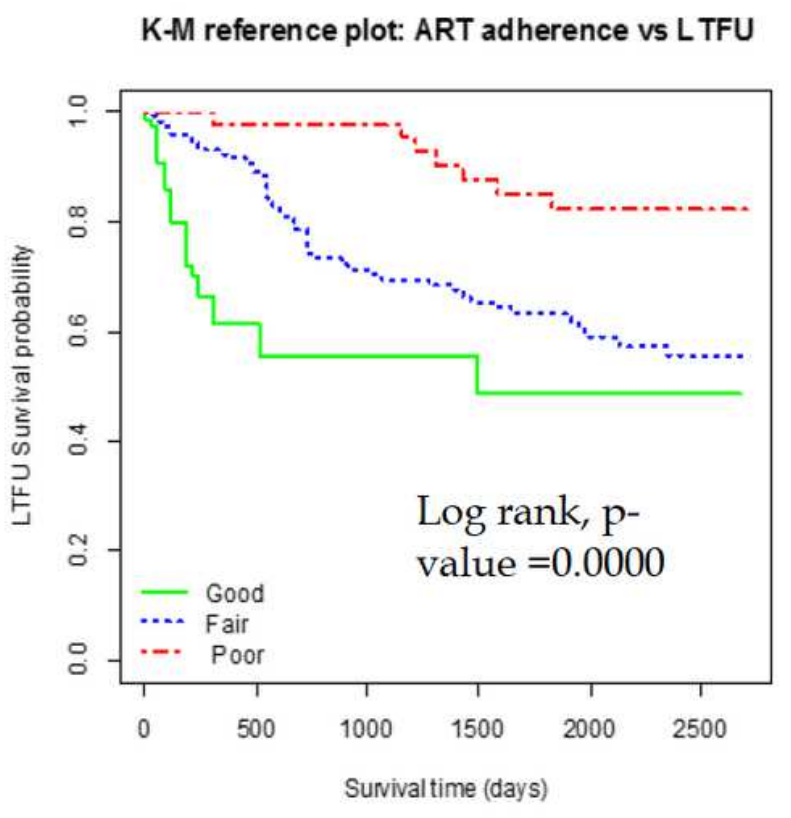

\section{K-M and Parametric plots for ART adherence vs LTFU}

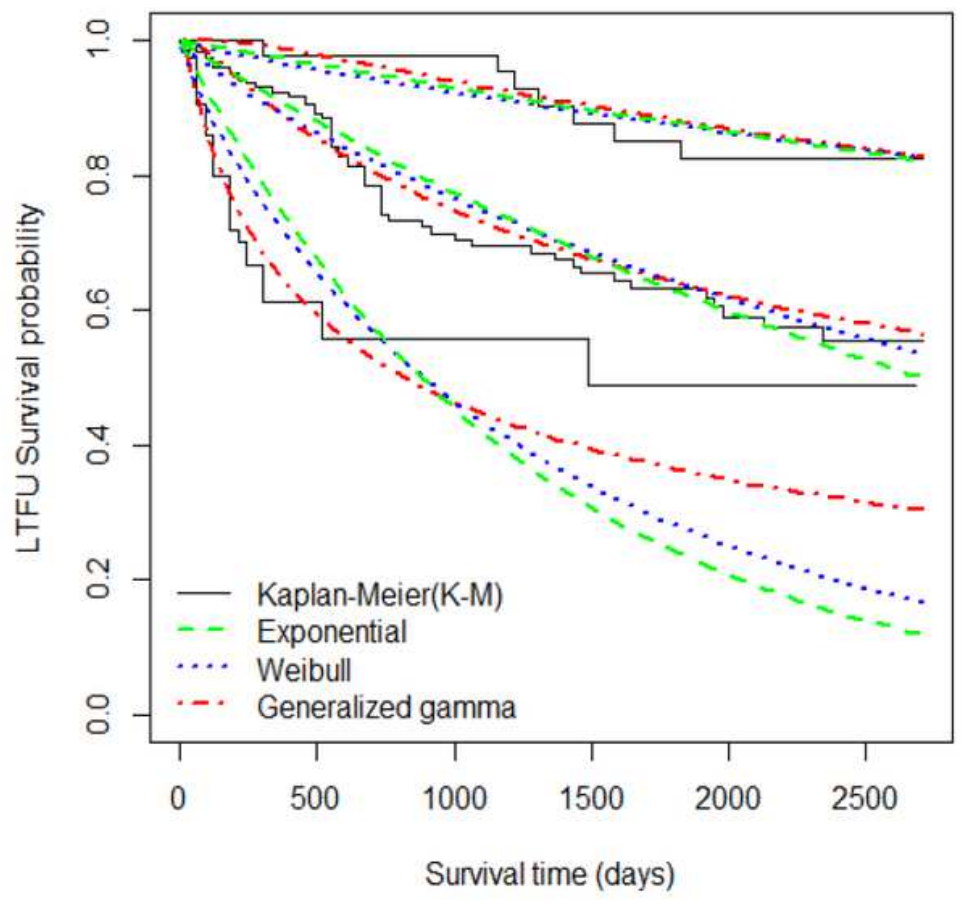

Figure 3

Kaplan Meier and parametric plots for estimated probabilities for the association bet ween ART adherence and loss to follow up 

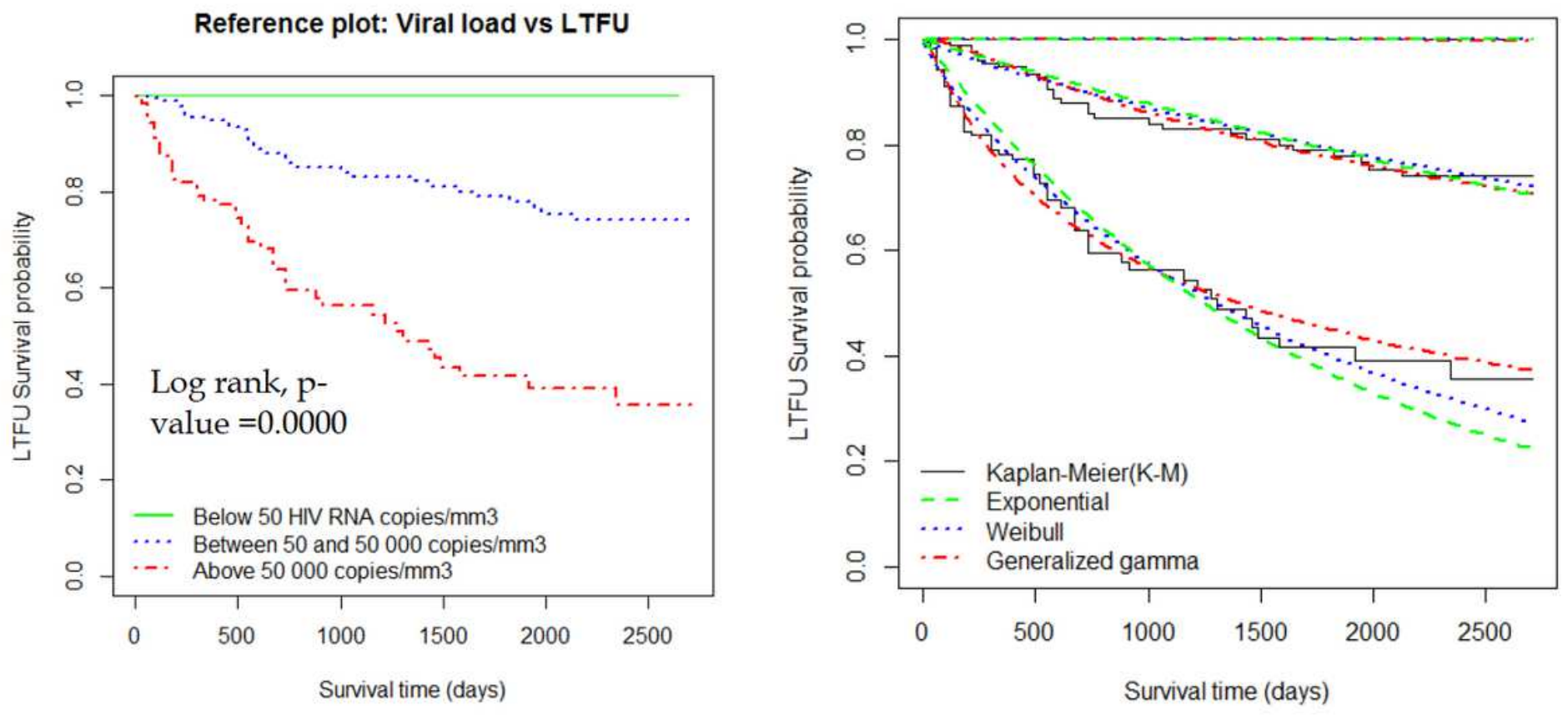

Figure 4

Kaplan Meier and parametric plots for estimated probabilities for the association between viral load and loss to follow up

K-M and Parametric plots for CD4 count vs LTFU

K-M reference plot: CD4 count vs LTFU

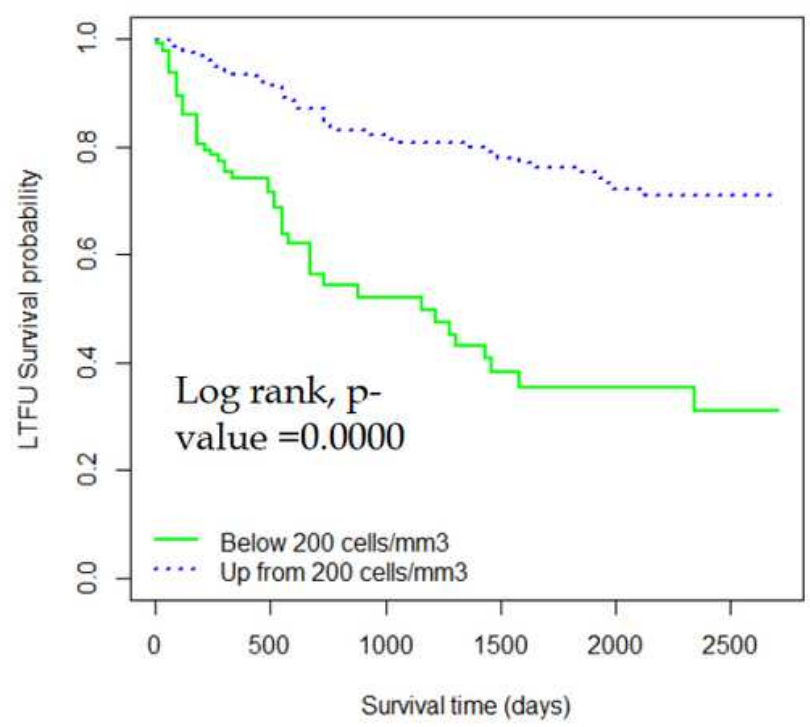

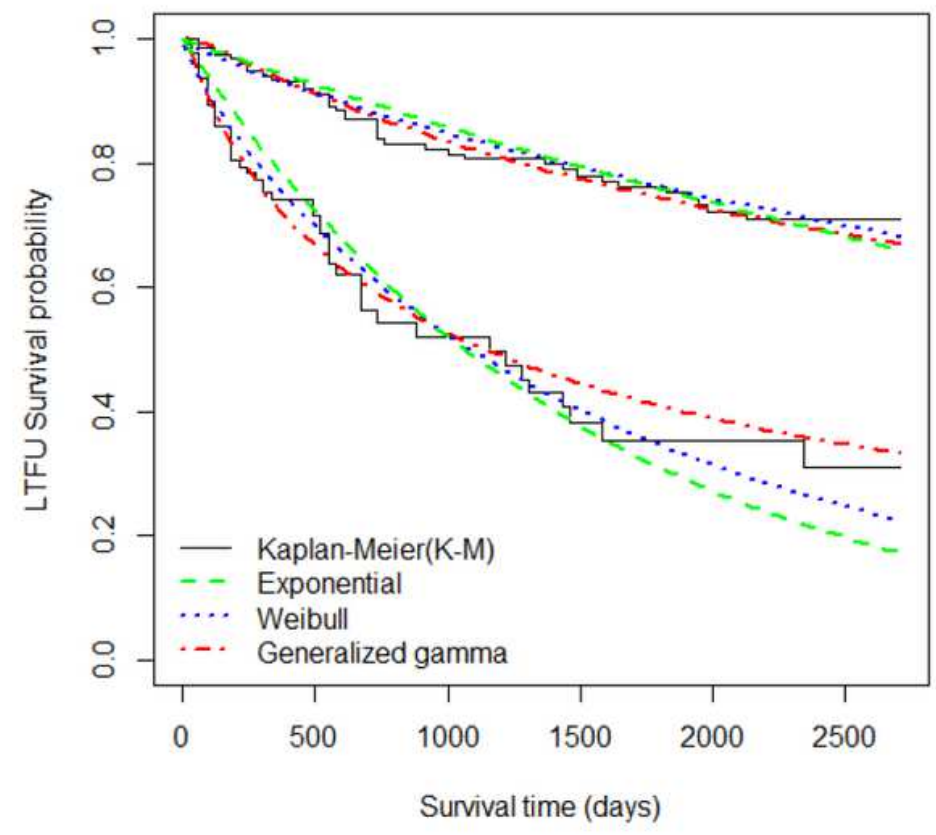

Figure 5 
Kaplan Meier and parametric plots for estimated probabilities for the association between CD 4 count and loss to follow up

\section{K-M and Parametric plots for Age group vs LTFU}
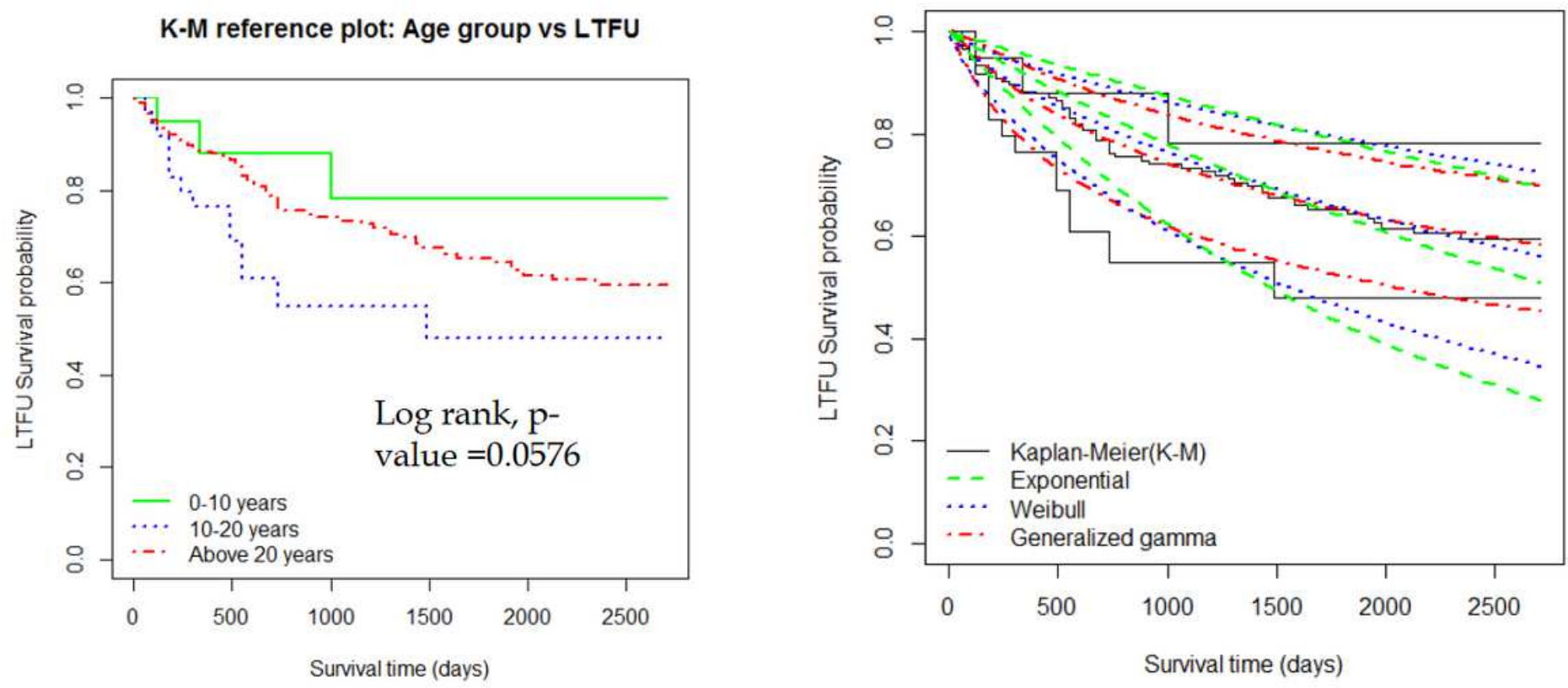

Figure 6

Kaplan Meier and parametric plots for estimated probabilities for the association between age group and loss to follow up 